\title{
Mechanisms underlying cell death in ischemia-like damage to the rat spinal cord in vitro
}

\author{
E Bianchetti ${ }^{1}$, M Mladinic ${ }^{1,2,3}$ and A Nistri ${ }^{\star, 1,2}$
}

New spinal cord injury (SCl) cases are frequently due to non-traumatic causes, including vascular disorders. To develop mechanism-based neuroprotective strategies for acute $\mathrm{SCl}$ requires full understanding of the early pathophysiological changes to prevent disability and paralysis. The aim of our study was to identify the molecular and cellular mechanisms of cell death triggered by a pathological medium (PM) mimicking ischemia in the rat spinal cord in vitro. We previously showed that extracellular $\mathrm{Mg}^{2+}(1 \mathrm{mM})$ worsened PM-induced damage and inhibited locomotor function. The present study indicated that $1 \mathrm{~h}$ of $\mathrm{PM}+\mathrm{Mg}^{2+}$ application induced delayed pyknosis chiefly in the spinal white matter via overactivation of poly (ADP-ribose) polymerase 1 (PARP1), suggesting cell death mediated by the process of parthanatos that was largely suppressed by pharmacological block of PARP-1. Gray matter damage was less intense and concentrated in dorsal horn neurons and motoneurons that became immunoreactive for the mitochondrial apoptosis-inducing factor (the intracellular effector of parthanatos) translocated into the nucleus to induce chromatin condensation and DNA fragmentation. Immunoreactivity to TRPM ion channels believed to be involved in ischemic brain damage was also investigated. TRPM2 channel expression was enhanced $24 \mathrm{~h}$ later in dorsal horn and motoneurons, whereas TRPM7 channel expression concomitantly decreased. Conversely, TRPM7 expression was found earlier $(3 \mathrm{~h})$ in white matter cells, whereas TRPM2 remained undetectable. Simulating acute ischemic-like damage in vitro in the presence of $\mathrm{Mg}^{2+}$ showed how, during the first $24 \mathrm{~h}$, this divalent cation unveiled differential vulnerability of white matter cells and motoneurons, with distinct changes in their TRPM expression.

Cell Death and Disease (2013) 4, e707; doi:10.1038/cddis.2013.237; published online 4 July 2013

Subject Category: Neuroscience

The clinical scenario of new spinal cord injury $(\mathrm{SCl})$ cases is changing because trauma is no more the leading cause. ${ }^{1}$ Non-traumatic SCl originates from vertebral stenosis, tumors, or cardiovascular disorders that comprise a cluster of postsurgical paralysis after abdominal aorta surgery. ${ }^{1}$ Although non-traumatic lesions are usually incomplete, the clinical symptoms are severe, and include paralysis and sensory dysfunction. A typical feature of $\mathrm{SCl}$ is the delayed onset of a secondary lesion, with cell death affecting the initially spared neighboring tissue through complex mechanisms. This is an important issue, as a prerequisite to the development of mechanism-based neuroprotective strategies for acute $\mathrm{SCl}$ is a detailed understanding of the early pathophysiological changes. On the assumption that brain lesions are transiently associated with decreased extracellular $\mathrm{Mg}^{2+}$ concentration, ${ }^{2}$ even if this observation has not been systematically confirmed in humans, ${ }^{3} \mathrm{Mg}^{2+}$ solution infusion was tested and was found to worsen the outcome in patients with traumatic brain lesions. ${ }^{4,5}$ This result was also observed in stroke patients. ${ }^{6}$ In accordance with this view are reports on the lack of effectiveness of exogenous $\mathrm{Mg}^{2+}$ on experimental $\mathrm{SCl}$ or neonatal brain injury. ${ }^{7,8}$

To explore the cell death mechanisms, our laboratory has developed an in vitro neonatal rat spinal cord model to mimic the metabolic perturbation (hypoxia, aglycemia, oxidative stress, acidosis, and toxic free radicals with low extracellular $\mathrm{Mg}^{2+}$ ) occurring in vivo after ischemic $\mathrm{SCl}^{9}$ This model is based on the transient application of a toxic medium (termed 'pathological medium', PM) that recapitulates the chief elements of metabolic dysfunction occurring in vivo and depresses locomotor network function with cell death predominantly in the white matter via an apoptotic pathway. We have observed that more extensive pyknosis with block of locomotor network activity is evoked when PM is applied with a standard concentration $(1 \mathrm{mM})$ of extracellular $\mathrm{Mg}^{2+10}$ when compared with preparations treated with Mg-free PM.

\footnotetext{
${ }^{1}$ Department of Neuroscience, International School for Advanced Studies (SISSA), Via Bonomea Trieste, Italy; ${ }^{2}$ SPINAL (Spinal Person Injury Neurorehabilitation Applied Laboratory), Istituto di Medicina Fisica e Riabilitazione, Udine, Italy and ${ }^{3}$ Department of Biotechnology, University of Rijeka, Rijeka, Croatia

${ }^{*}$ Corresponding author: A Nistri, Department of Neuroscience, International School for Advanced Studies (SISSA), Via Bonomea 265, Trieste 34136, Italy. Tel: + 39040 3787718; Fax: + 39040 3787702; E-mail: nistri@ sissa.it

Keywords: magnesium; PAR; AIF; parthanatos; TRPM2; TRPM7

Abbreviations: AIF, apoptosis-inducing factor; AUs, arbitrary units; ChAT, choline acetyltransferase; DAPI, 4,6-diamidino-2-phenylindole; DTT, dithiothreitol; EDTA, ethylenediaminetetraacetic acid; ELISA, enzyme-linked immunosorbent assay; H2AX, phospho-histone2A.X(Ser139); HEPES, 4-(2-hydroxyethyl)-1-piperazineethanesulfonic acid; L3, lumbar spinal cord segment 3; NeuN, neuronal nuclei; PM, pathological medium; PBS, phosphate-buffered solution; PJ34, N-(5,6-dihydro-6-oxo-2phenanthridinyl)-2-acetamide; PMSF, phenylmethylsulfonyl fluoride; SNP, sodium nitroprusside; SCI, spinal cord injury; PAR, poly-ADP-ribose; PARP-1, poly (ADP-ribose) polymerase 1; ROI, region of interest; SMI 32, neurofilament $\mathrm{H}$ non-phosphorylated monoclonal antibody; T13, thoracic spinal cord segment 13; TRIS, tromethamine; TRPM2, transient receptor potential cation channel, subfamily M, member 2; TRPM7, transient receptor potential cation channel, subfamily M, member 7 Received 27.3.13; revised 28.5.13; accepted 03.6.13; Edited by A Verkhratsky
} 
Although $\mathrm{Mg}^{2+}$ is essential for numerous enzymatic reactions, ${ }^{11}$ novel targets of $\mathrm{Mg}^{2+}$ on the central nervous system have emerged. In particular, $\mathrm{Mg}^{2+}$ gates the activity of TRPM7, a bifunctional protein containing a protein kinase fused to an ion channel ${ }^{12}$ and having a key role in neuronal death caused by oxidative stress and excitotoxicity. ${ }^{13}$ Further, TRPM2 (a member of the same channel family and modulated by $\mathrm{Mg}^{2+}$ ) is involved in the delayed death of brain neurons after experimental ischemia. ${ }^{13-15}$ The aim of the present report was to investigate whether the increased severity of spinal damage evoked by $\mathrm{PM}+\mathrm{Mg}^{2}+$ was due to recruitment of additional cell death pathways, as well as study their identity and the potential involvement of TRPM2 and TRPM7.

\section{Results}

Cell death induced by $\mathbf{P M}+\mathbf{M g}^{\mathbf{2}+}$. Our previous report ${ }^{10}$ indicated that a 1-h application of PM containing $1 \mathrm{mM} \mathrm{Mg}^{2+}$ induces, $24 \mathrm{~h}$ later, significant damage to the in vitro spinal cord. This observation was confirmed by detecting extensive pyknosis in the white matter region at $24 \mathrm{~h}$ (see arrow in the example of Figure 1a). Figure $1 \mathrm{~b}$ indicates the four ROIs used for these experiments, whereas Figure 1c quantifies these data. Significant pyknosis already emerged $3 \mathrm{~h}$ after washing out the toxic medium (Figure 1c). It is noteworthy that sham preparations (kept in standard Krebs for up to $24 \mathrm{~h}$ ) or mock preparations (bathed for $1 \mathrm{~h}$ in Mg-free Krebs solution to which $1 \mathrm{mM} \mathrm{Mg}^{2+}$ was added to test for any artifact due to solution application and washout procedure) showed no significant pyknosis (Figure 1c). Thus, unlike the outcome with PM without $\mathrm{Mg}^{2+}$ (Figure 1c), the presence of this divalent cation worsened an ischemia-like metabolic perturbation, and cell damage developed over $24 \mathrm{~h}$.

Characterization of the white matter damage evoked by $\mathbf{P M}+\mathbf{M g}^{\mathbf{2}+}$. Using biomarkers previously employed to characterize spinal injury, ${ }^{16,17}$ we next investigated the type of cell damage evoked by $\mathrm{PM}+\mathrm{Mg}^{2+}$ by studying immunoreactivity to phospho-histone2A.X(Ser139) (H2AX a marker of DNA double-strand breaks) ${ }^{18}$ and active-caspase 3 (a marker of apoptosis) ${ }^{19}$ in the white matter ROI where extensive pyknosis was found (Figure 1c). Figure 2a shows that the percentage of $\mathrm{H} 2 \mathrm{AX}$-positive cells in the white matter region was higher in treated than in sham preparations at 3 or $24 \mathrm{~h}$. Nevertheless, unlike the number of pyknotic nuclei (Figure 1c), the number of H2AX-positive elements did not increase from 3 to $24 \mathrm{~h}$ (Figure $2 \mathrm{a}$ ), suggesting the presence of early DNA double-strand lesions in keeping with former studies. ${ }^{18,20}$ By comparing the 24-h data in Figures $1 \mathrm{c}$ and $2 \mathrm{a}$, it seems likely that the $\mathrm{PM}+\mathrm{Mg}^{2+}$ damage affected the vast majority of white matter elements, as about $75 \%$ of them showed pyknosis and $25 \%$ had $\mathrm{H} 2 \mathrm{AX}$ immunoreactivity. Interestingly, in the same ROI, immunopositivity for active caspase 3 (an important executor of apoptosis), although limited to $<5 \%$ of the cells, was larger than that in the sham condition (Figure $2 b$ ).

The poor expression of active caspase 3 was an unexpected result, as PM (without $\mathrm{Mg}^{2+}$ ) is known to damage the spinal white matter primarily via caspase-dependent apoptosis. $^{16}$ When the spinal damage is evoked by excitotoxicity, the main process of cell death is a non-apoptotic mechanism termed parthanatos caused
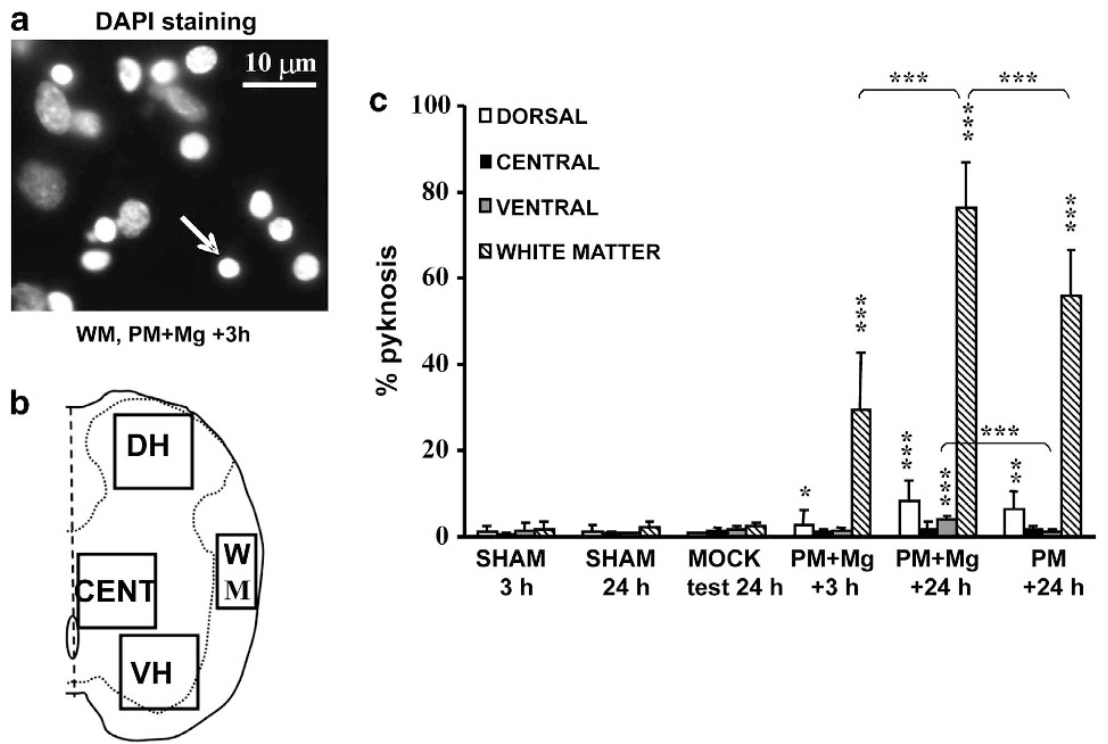

Figure 1 Pyknosis in the rat spinal cord in vitro following transient (1 h) application of pathological medium with or without Mg ${ }^{2+}$. (a) Example of the spinal cord pyknosis (see arrow) in the white matter $3 \mathrm{~h}$ after washout of $\mathrm{PM}+\mathrm{Mg}^{2}+$. Scale bar: $10 \mu \mathrm{m}$. (b) Schematic representation of the four spinal ROls used for analysis. DH, dorsal horn; CENT, central area; VH, ventral horn; WM, white matter. (c) Histograms show percentage of pyknotic cells in the four ROls shown in (b). Mock data refer to preparations in which washout of incubating medium was performed to test for any potential mechanical damage related to this procedure. Note: statistically significant increase in the white matter pyknotic cell number in the samples treated with PM with or without $\mathrm{Mg}^{2+}$ versus sham preparations at 3 or $24 \mathrm{~h}$ after washout. Data are the average taken from nine sections from three rats. The Mann-Whitney test was used after performing an ANOVA Tukey test; ${ }^{*} P=0.022 ;{ }^{* *} P=0.004 ;{ }^{* \star *} P<0.001$ 
a
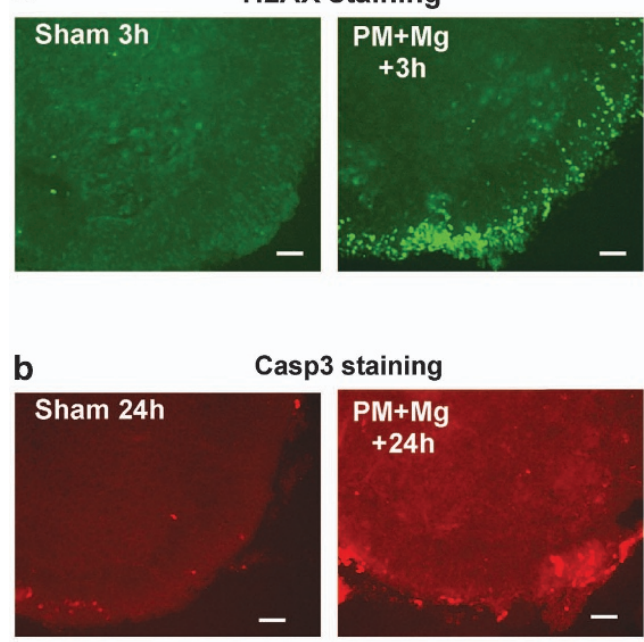

Casp3 staining
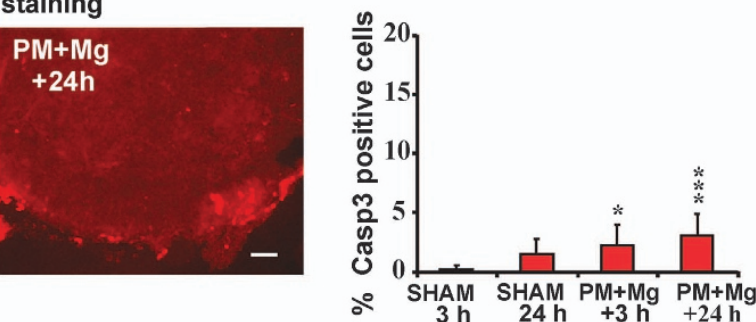
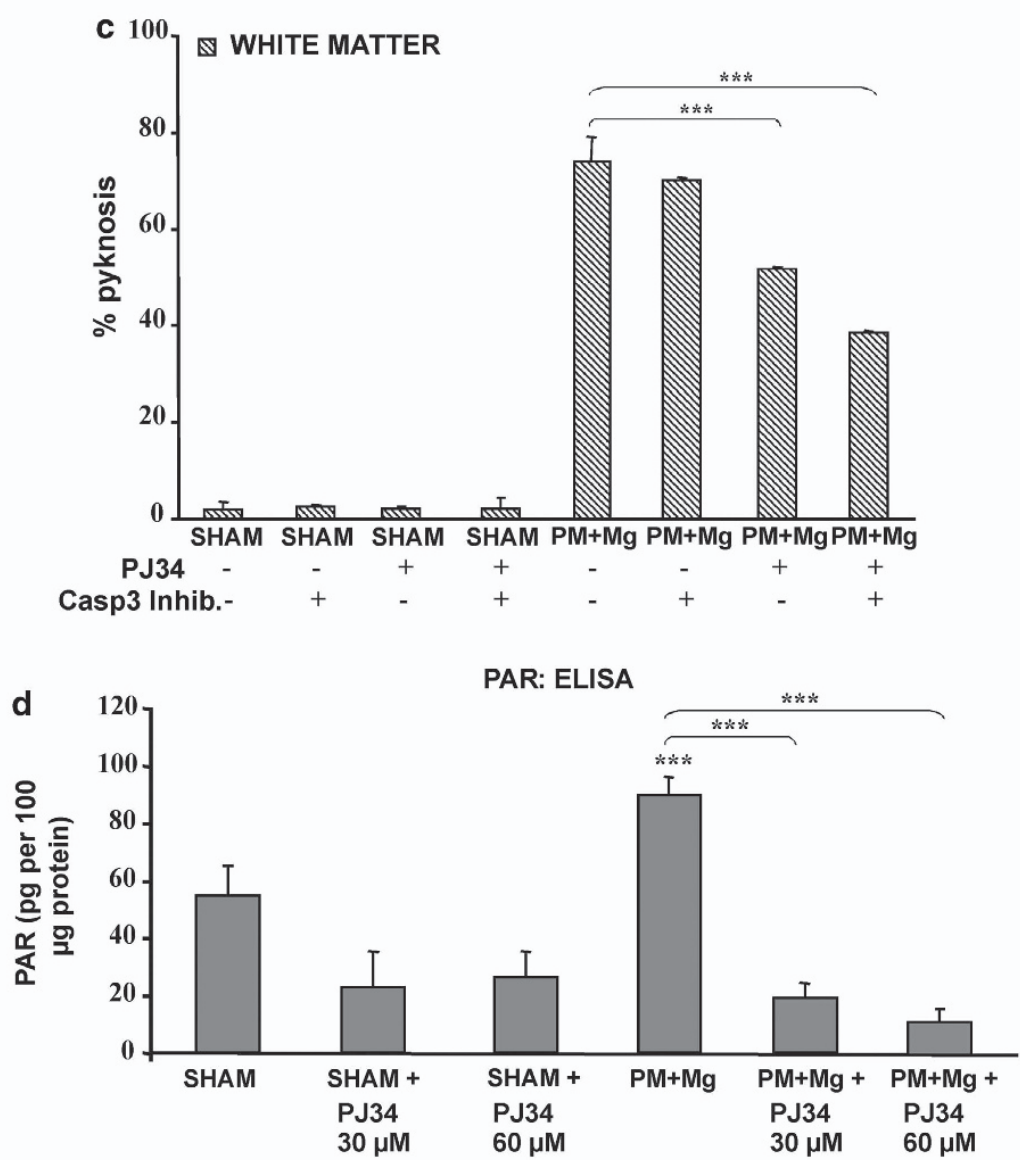

Figure 2 Characterization of white matter damage evoked by $\mathrm{PM}+\mathrm{Mg}^{2+}$. (a) Left, examples of immunostaining for $\mathrm{H} 2 \mathrm{AX}$ in the ventral quadrant of the spinal cord in which the white matter shows minimal signal positivity in sham conditions. Scale bar: $30 \mu \mathrm{m}$; right, percentage of $\mathrm{H} 2 \mathrm{AX}$-positive cells in the ventrolateral white matter after $\mathrm{PM}+\mathrm{Mg}^{2+} ; n=9$ sections, ${ }^{\star \star \star} P<0.001$. (b) Left, examples of immunostaining for active caspase 3 in the same ROls as shown in (a); right, percentage of caspase 3 positive cells in the ventrolateral white matter after $\mathrm{PM}+\mathrm{Mg}^{2+} ; n=9$ sections, ${ }^{*} P=0.034 ;{ }^{* \star *} P<0.001$. (c) Histograms showing pyknotic nuclei after addition (on $\mathrm{PM}+\mathrm{Mg}^{2+}$ washout) of caspase 3 inhibitor $(1 \mu \mathrm{M}), \mathrm{PJ} 34(60 \mu \mathrm{M})$, or both. $n=9$; ${ }^{* * *} P<0.001$. For data shown in $(\mathbf{a}),(\mathbf{b})$ and $(\mathbf{c})$, the Mann-Whitney test was used after performing an ANOVA Tukey test. (d) Histograms show PAR tissue levels in various experimental conditions. For each test, data are from three spinal cords tested in duplicate; one-way Anova Tukey test; ${ }^{* *} P<0.001$ 
by excessive activation of PARP-1 (poly (ADP-ribose) polymerase 1) to synthesize toxic concentrations of PAR (poly-ADP-ribose) that disrupt cell energy stores. ${ }^{21}$ Therefore, in the present report we investigated whether, in the white matter $\mathrm{ROI}, \mathrm{PM}+\mathrm{Mg}^{2+}$ could stimulate excessive production of PAR, which is known to induce pyknosis. ${ }^{21,22}$ Thus, we tested whether application of a selective inhibitor of either PARP-1 activity or caspase-3 might protect white matter elements from $\mathrm{PM}+\mathrm{Mg}^{2+}$ toxicity. To this end, we used PJ34 (N-(5,6-dihydro-6-oxo-2-phenanthridinyl)-2-acetamide) to block PARP $-1^{23}$ and the caspase peptide inhibitor (caspase 3 inhibitor II, Z-DEVD-fmk) to block apoptosis, ${ }^{24}$ which were applied (for $24 \mathrm{~h}$ ) either alone or in combination immediately after washing out $\mathrm{PM}+\mathrm{Mg}^{2+}$. Figure $2 \mathrm{c}$ summarizes these data: whereas the caspase inhibitor alone did not significantly reduce pyknosis (5\% change; see Figure 2c), PJ34 significantly $(P<0.001)$ decreased pyknosis by $>25 \%$, an effect even stronger ( $>35 \%$ ) when the two pharmacological blockers were applied together $(P<0.001)$, indicating partial convergence of these two cell death processes. Neither inhibitor had any effect on sham preparations (Figure 2c). Figure 2d indicates that PJ34 applied at a concentration of $60 \mu \mathrm{M}$ was a strong inhibitor of the tissue generation of PAR measured with an enzyme-linked immunosorbent assay (ELISA). Halving the concentration of PJ was less effective.

Figure $3 a$ illustrates an example of co-staining with 4,6-diamidino-2-phenylindole (DAPI) and the PAR antibody of a pyknotic white matter cell $24 \mathrm{~h}$ after $\mathrm{PM}+\mathrm{Mg}^{2+}$ application. Figure $3 \mathrm{~b}$ shows that, among the total DAPI-stained elements, the percentage of PAR-positive cells in white matter ROI (hatched bars) had already increased significantly $(P<0.001)$ $3 \mathrm{~h}$ after $\mathrm{PM}+\mathrm{Mg}^{2+}$, and it remained elevated $(P<0.001) 24 \mathrm{~h}$ later. Figure $3 b$ (filled bars) also quantifies co-occurrence of PAR immunopositivity together with pyknosis for the total number of pyknotic cells; it is clear that $\mathrm{PM}+\mathrm{Mg}^{2+}$ induced a significant $(P<0.001)$ increase in the association between PAR and pyknosis at 3 and $24 \mathrm{~h}$. In fact, few cells were PAR positive without pyknotic nucleus at either time (open bars). This finding suggested that $\mathrm{PM}+\mathrm{Mg}^{2+}$ had transformed the white matter damage from the apoptosis previously detected with PM alone ${ }^{10}$ to a process with parthanatos characteristics. We thus wondered whether an analogous process might have developed in the gray matter.

Characterization of gray matter damage evoked by PM + $\mathbf{M g}^{2+}$. Despite the comparatively modest extent of the lesion to the gray matter induced by $\mathrm{PM}+\mathrm{Mg}^{2+}$ (see Figure 1c), this protocol is known to inhibit locomotor network function. ${ }^{10}$ To further analyze neuronal damage, the present study quantified the percentage of NeuN-positive neurons in dorsal, central, and ventral ROls at 3 and $24 \mathrm{~h}$ after $\mathrm{PM}+\mathrm{Mg}^{2+}$. Figure 4 demonstrates that significant neuronal loss was absent at $3 \mathrm{~h}$, and became apparent at $24 \mathrm{~h}$ as far as the dorsal and ventral ROIs were concerned. Thus, in accordance with pyknosis data (Figure 1c), PM+ $\mathrm{Mg}^{2+}$ had an early effect on white matter elements, and a later one on gray matter cells, which, in the ventral horn, constitute a small minority of the spinal cell population. ${ }^{25}$

As, among gray matter regions, the late damage by $\mathrm{PM}+$ $\mathrm{Mg}^{2+}$ appeared to mostly affect the ventral ROI that contains
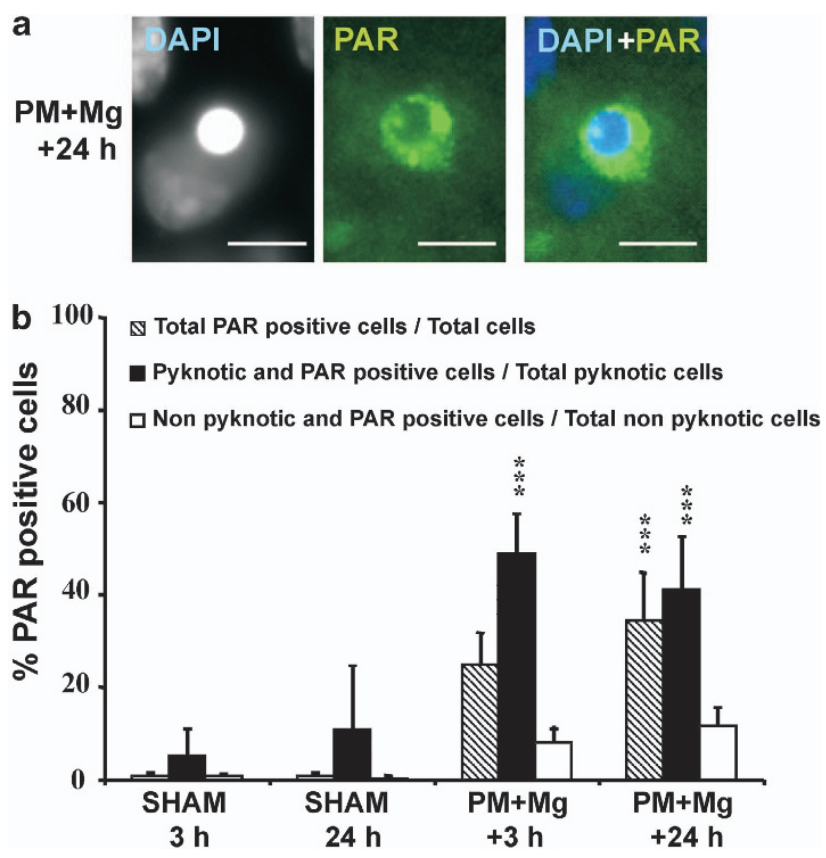

Figure 3 PAR immunoreactivity in the white matter after $\mathrm{PM}+\mathrm{Mg}^{2+}$. (a) Example of co-staining with DAPI (left) and PAR immunoreactivity (middle) of a pyknotic white matter cell $24 \mathrm{~h}$ after $\mathrm{PM}+\mathrm{Mg}^{2+}$ application; right panel shows overlapped images; scale bar: $10 \mu \mathrm{m}$. (b) Histograms show percentage of PAR-positive cells (hatched bars) over total DAPI-stained elements, co-occurrence of PAR immunopositivity and pyknosis (filled bars) and total number of pyknotic cells (open bars). $n=9$; the Mann-Whitney test was used after performing an ANOVA Tukey test; ${ }^{* * \star} P<0.001$

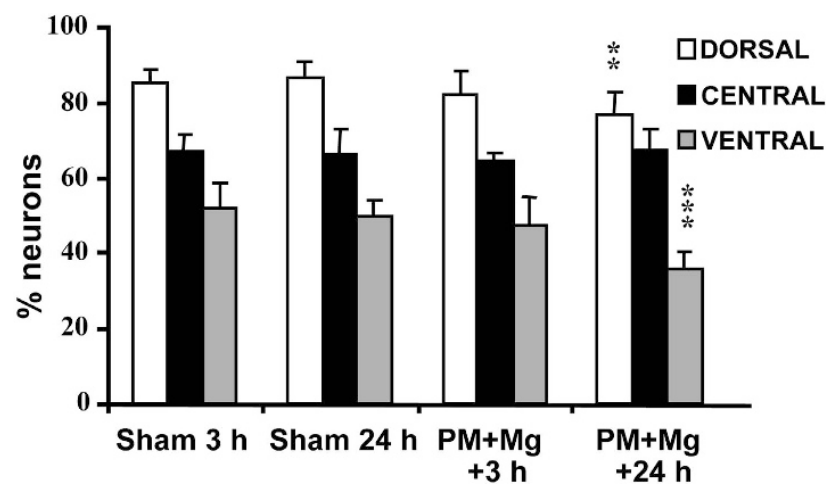

Figure 4 Characterization of neuronal damage evoked by $\mathrm{PM}+\mathrm{Mg}^{2+}$. Histograms show percentage of neurons (NeuN-positive cells) observed in three ROls in control or after PM $+\mathrm{Mg}^{2+}$ washout ( 3 or $24 \mathrm{~h}$ ). The Mann-Whitney test was used after performing an ANOVA Tukey test, $n=9 ;{ }^{* \star} P=0.003 ;{ }^{* \star} P<0.001$

motoneurons, namely, the essential output elements of the locomotor network, we next investigated dysfunctional changes in motoneurons, identified as large ( $>25 \mu$ m somatic diameter) cells located in the ventral horn and immunopositive for choline acetyltransferase (ChAT, the cytoplasmic ACh synthetic enzyme), and for SMI32, a marker for motoneuron cytoskeleton. ${ }^{26,27}$ Figure 5a shows that the number of ChATpositive motoneurons did not change following $\mathrm{PM}+\mathrm{Mg}^{2+}$ at 3 or $24 \mathrm{~h}$, whereas the average intensity of the SMI32 signal was significantly $(P<0.001)$ decreased at 3 and $24 \mathrm{~h}$ (Figure 5b). This observation suggests that, despite the 

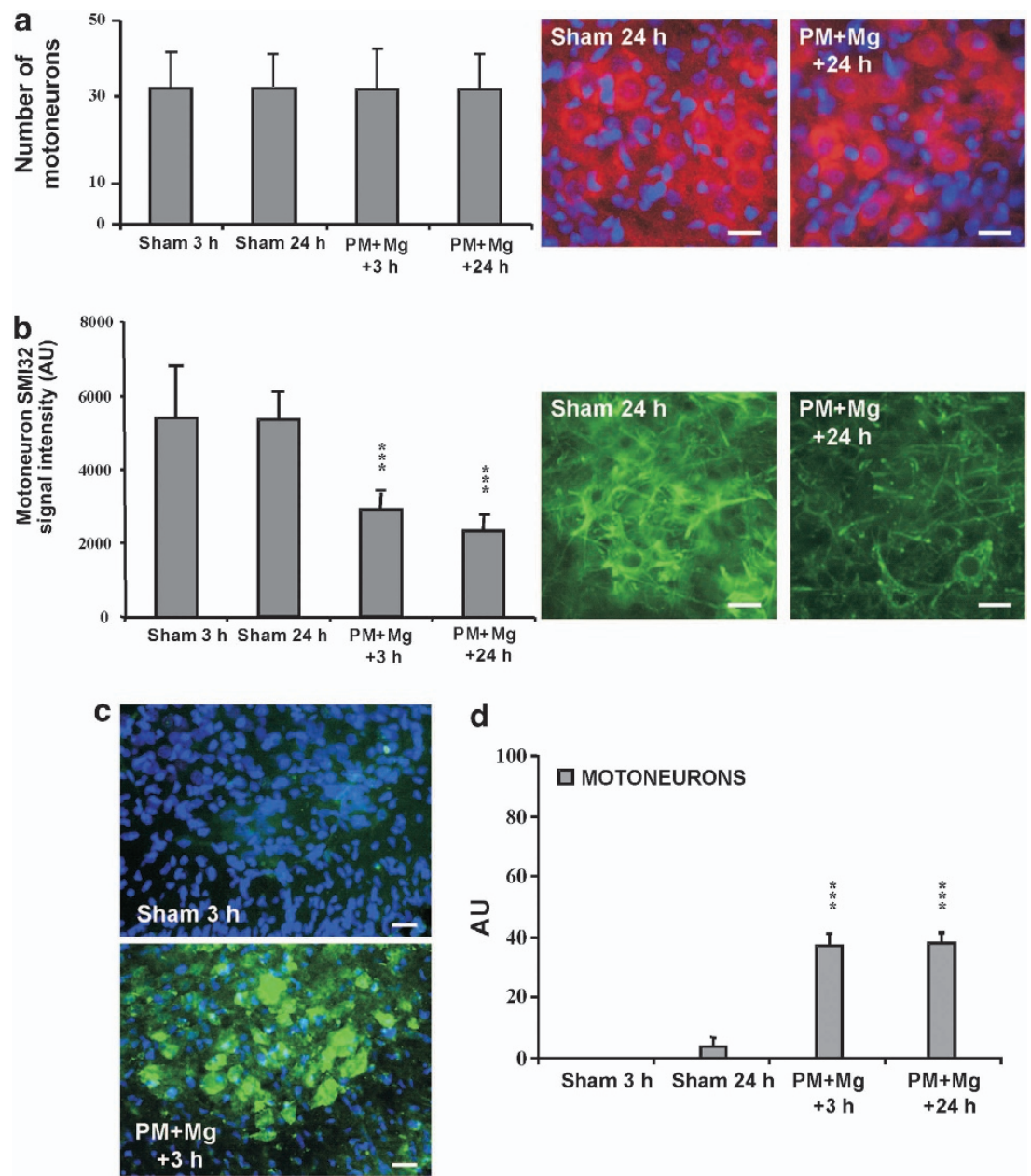

d

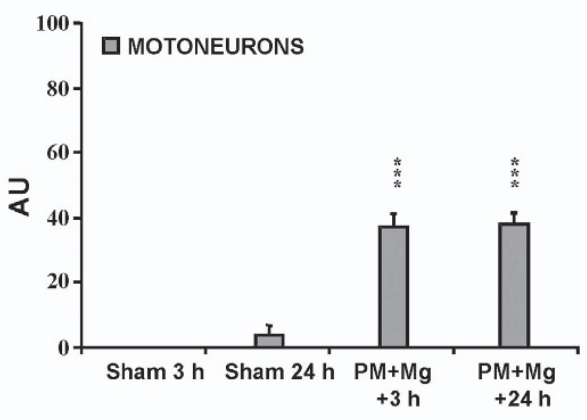

Figure 5 Characterization of motoneuron damage evoked by $\mathrm{PM}+\mathrm{Mg}^{2+}$. (a) Histograms show motoneuron numbers counted with ChAT immunostaining. Inset shows an example of ChAT-stained ventral horn cells in sham-24 or PM $+\mathrm{Mg}-24$ conditions. Bar $=30 \mu \mathrm{m}$. (b) Histograms show motoneuron SMI 32 signal intensity that was already decreased $3 \mathrm{~h}$ after $\mathrm{PM}+\mathrm{Mg}^{2+}$ washout; a $t$-test was performed after an ANOVA Tukey test; ${ }^{* \star *} P<0.001$. Inset shows an example of SMI32-stained ventral horn cells in sham- $24 \mathrm{~h}$ or $\mathrm{PM}+\mathrm{Mg}-24 \mathrm{~h}$ conditions. Bar $=30 \mu \mathrm{m}$. (c) Examples of PAR immunoreactivity detected in motoneurons $3 \mathrm{~h}$ after $\mathrm{PM}+\mathrm{Mg}^{2+} ; \mathrm{scale}$ bar: $30 \mu \mathrm{m}$. (d) Histograms show motoneuron PAR signal intensity enhanced after $\mathrm{PM}+\mathrm{Mg}^{2+}$; a Mann-Whitney test was performed after an ANOVA Tukey test, ${ }^{* * *} P<0.001$. For all experiments, data are from nine spinal sections from three rats

unaltered number of motoneurons, these cells showed signs of cytoskeleton damage.

Neuronal distress can strongly activate PARP-1 to generate toxic levels of PAR ('parthanatos'). ${ }^{28,29}$ In accordance with this notion, a significant increase in PAR immunoreactivity was detected in motoneurons early after $\mathrm{PM}+\mathrm{Mg}^{2+}$, as exemplified in Figure $5 \mathrm{c}$ and quantified in Figure $5 \mathrm{~d}$. It is noteworthy that the PAR signal intensity did not increase further at $24 \mathrm{~h}$.

The toxic action of PAR is typically executed via translocation of the transcription factor apoptosis-inducing factor (AIF) from the mitochondria to the nucleus ${ }^{22,29,30}$ and it thus represents a delayed cell death signal. We examined the expression and translocation of AIF in motoneurons as indicated in Figures $6 a$ and b. In sham conditions, the confocal line scan of the motoneuron cell body (see line across cell soma in Figure 6a, left) demonstrated that its DAPI staining was confined to the cell nucleus (blue line; Figure $6 \mathrm{a}$, right), whereas AIF (red line in Figure 6a, right) was poorly expressed throughout the cell. In contrast, $24 \mathrm{~h}$ after PM + $\mathrm{Mg}^{2+}$ (Figure 6b), whereas DAPI staining was still restricted to the nucleus, AIF immunoreactivity was diffused and extended to the cell nucleus as well. Detection of AIF in the motoneuron nucleus was accompanied by loss of expression of the nuclear transcription factor NeuN as shown in Figure $6 \mathrm{c}$ (see open arrow). Finally, Figure $6 \mathrm{~d}$ indicates that, $24 \mathrm{~h}$ after $\mathrm{PM}+\mathrm{Mg}^{2+}$, about $30 \%$ of motoneurons showed AIF nuclear translocation. All together, these observations suggest that, despite the persistence of ChAT immunoreactivity, a significant fraction of motoneurons displayed multiple signs of distress $24 \mathrm{~h}$ after $\mathrm{PM}+\mathrm{Mg}^{2+}$, consistent with the onset of a parthanatos-like process.

\section{Expression of TRPM7 or TRPM2 after $\mathrm{PM}+\mathrm{Mg}^{+}$} application. TRPM7 and TRPM2 are members of a large family of ion channels ${ }^{31}$ believed to play an important role in the neurodegeneration evoked by ischemia in vivo or by ischemia-like conditions in vitro. ${ }^{13,14,32-35}$ In the present study, we found undetectable TRPM7 immunopositivity in the white matter from freshly frozen preparations (Figure $7 \mathrm{a}$, open circle), or under 3 and $24 \mathrm{~h}$ sham conditions (Figure $7 \mathrm{a}$, 

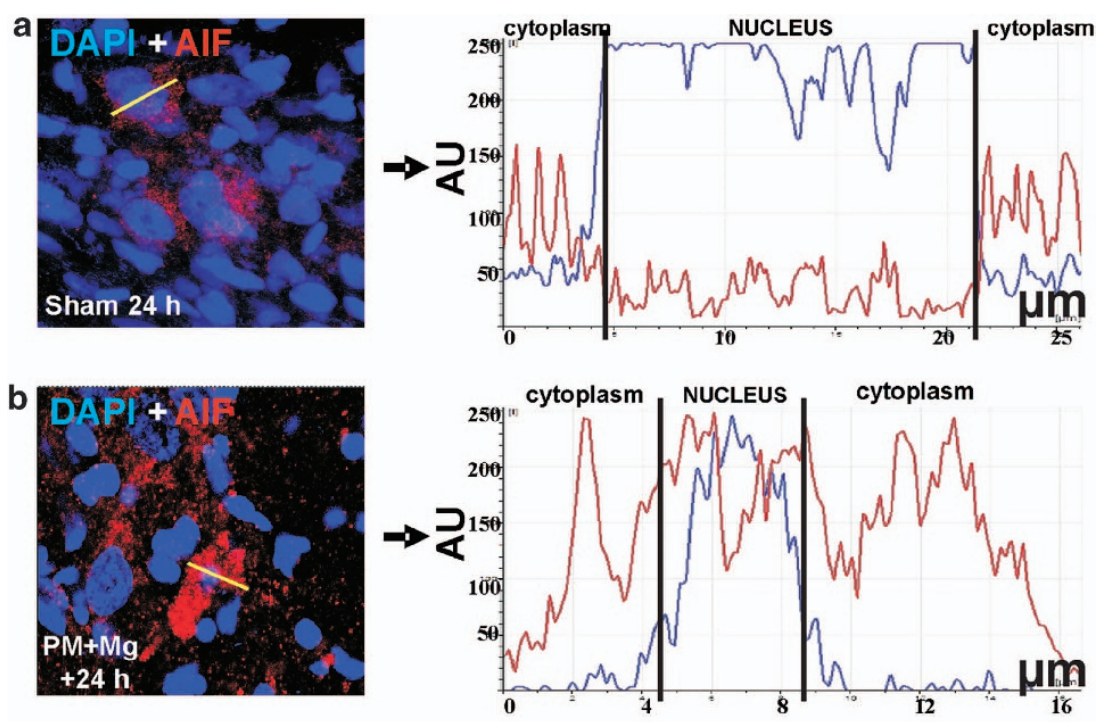

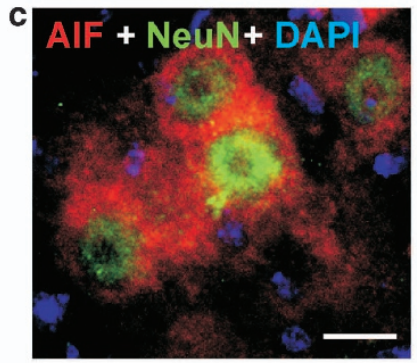

SHAM $24 \mathrm{~h}$

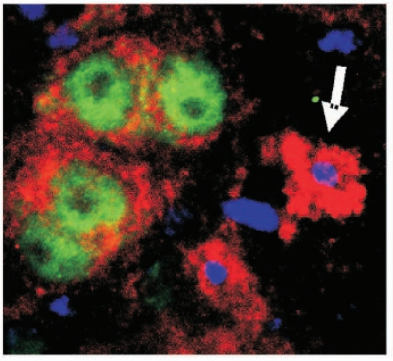

$\mathrm{PM}+\mathrm{Mg}+24 \mathrm{~h}$

d $\quad \%$ motoneurons with nuclear AIF

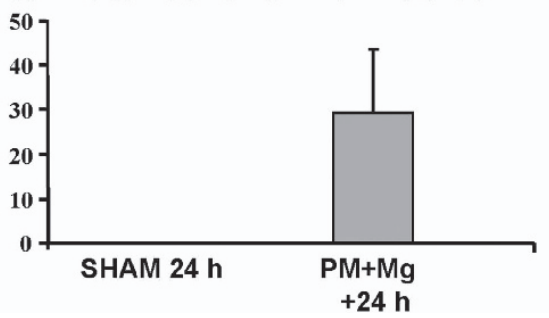

Figure 6 AIF signal in motoneurons after PM $+\mathrm{Mg}^{2+}$. (a) An example of AIF cytoplasmic distribution in sham motoneurons (left), with confocal line scan analysis plotted on the right for the cell indicated by an open bar on the left. Note strong nuclear distribution of DAPI (blue) versus AIF. (b) Analogous presentation of data referred to sample $24 \mathrm{~h}$ after PM $+\mathrm{Mg}^{2+}$. Note DAPI signal colocalized with AIF in the nucleus. (c) Examples of DAPI (blue) co-staining with AIF (red; left columns) or NeuN (green; right columns) under sham conditions (top row) or after PM $+\mathrm{Mg}^{2+}$ (bottom row). Under sham conditions, the AIF signal was cytoplasmic and the NeuN signal was nuclear. After $\mathrm{PM}+\mathrm{Mg}^{2+}$, the AIF signal is expressed by the motoneuron nucleus that has lost NeuN immunoreactivity. Scale bar: $30 \mu \mathrm{m}$. (d) Histograms show percentage of motoneurons expressing nuclear AIF after $\mathrm{PM}+\mathrm{Mg}^{2}$. For all experiments, data are from nine spinal sections from three rats (see white arrow)

open squares), or immediately after washing out $\mathrm{PM}+\mathrm{Mg}^{2+}$ (Figure 7a, filled triangle). Vice versa, a strong signal became apparent $3 \mathrm{~h}$ after $\mathrm{PM}+\mathrm{Mg}^{2+}$ washout and remained stable $24 \mathrm{~h}$ later (Figure 7a, filled triangles). White matter TRPM7 immunoreactivity was most frequently detected in pyknotic cells (see arrows in Figure $7 \mathrm{~b}$ ) as quantified in Figure 7c (filled bars). In the white matter ROI, there was no significant TRPM2 immunoreactivity under treated or sham conditions (not shown). Thus, it appeared that about half of the white matter elements that died (pyknosis) after PM+ $\mathrm{Mg}^{2+}$ treatment also expressed strong positivity to TRPM7.

In contrast to these data from the white matter ROI, in the three gray matter ROIs we found baseline positivity to TRPM7
(Figures 8a and b) and TRPM2 (Figure 8c). After washing out $\mathrm{PM}+\mathrm{Mg}^{2+}$, the TRPM7signal was found significantly lower $24 \mathrm{~h}$ later (Figures 8a and b) in the dorsal horn ROI $(P<0.001)$ and in the motoneuron $\mathrm{ROI}(P=0.002)$. Conversely, for the same ROls, TRPM2 immunopositivity appeared to move in the opposite direction with a delayed increase $24 \mathrm{~h}$ after washing out $\mathrm{PM}+\mathrm{Mg}^{2+}$ (Figure $8 \mathrm{c}$ ).

\section{Discussion}

The focus of the present study was the role of extracellular $\mathrm{Mg}^{2+}$ in the genesis of cell death after transient application of a solution mimicking ischemia conditions. The present data 

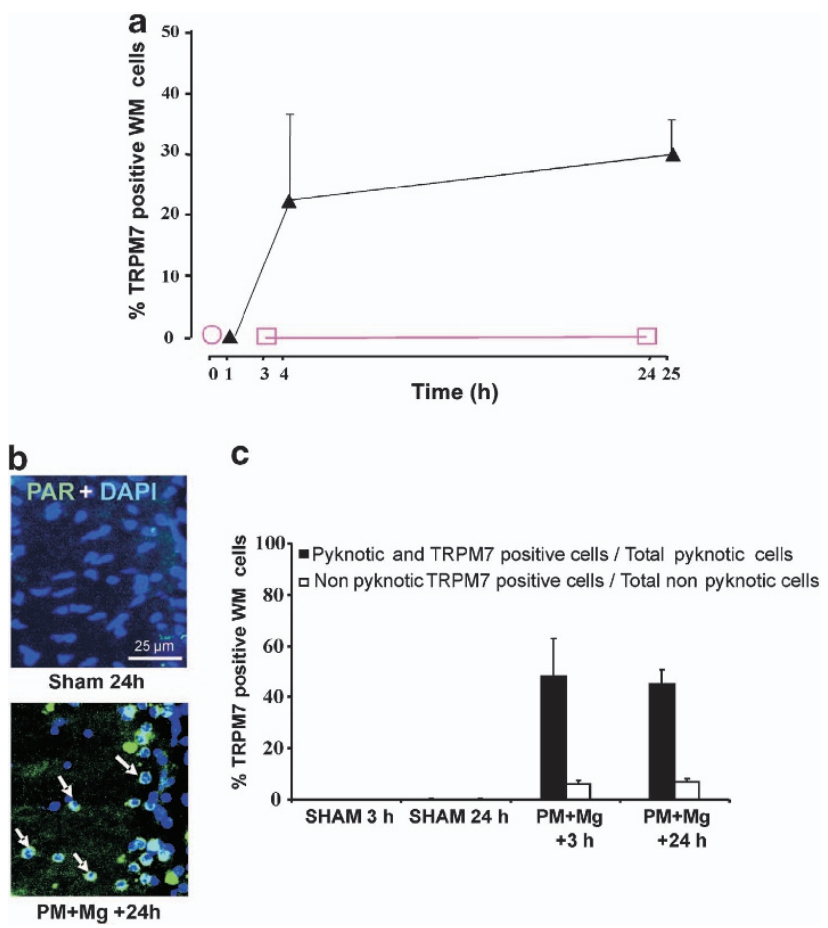

Figure 7 White matter expression of TRPM7 after PM $+\mathrm{Mg}^{2+}$ application. (a) Plot of the number of TRPM7-positive white matter cells against time following $\mathrm{PM}+\mathrm{Mg}^{2+}$ (filled triangles). TRPM7 immunopositivity was undetectable in the white matter from freshly frozen preparations (open circle at time 0 ) or under sham conditions (open squares at 3 and $24 \mathrm{~h}$ ). (b) Examples of TRPM7-positive white matter cells (see arrows) after $\mathrm{PM}+\mathrm{Mg}^{2+}$. (c) Histograms show percentage of TRPM7-positive/pyknotic white matter cells calculated with respect to the total number of pyknotic elements (filled bars). Open bars show percentage of TRPM7positive cells without pyknosis over total number of non-pyknotic cells. We also quantified co-occurrence of TRPM7 immunopositivity together with pyknosis for the total number of pyknotic cells. All data are from nine spinal sections from three rats

indicate that the presence of this divalent cation contributed to enhancing and widening the delayed damage to the white and gray matters of the rat spinal cord by facilitating a distinct cell death pathway.

A model of non-traumatic injury. The growing number of non-traumatic causes of $\mathrm{SCl}^{1}$ led us to examine the processes responsible for early cell death after the in vitro insult. Our previous investigations indicated that applying a toxic solution containing free oxygen radicals with no oxygen or glucose supply especially damaged the white matter elements, with moderate impairment of locomotor-like patterns that were still present at regular frequency but with clearly lower amplitude. ${ }^{9,10}$ Nevertheless, when the same toxic solution contained the standard extracellular $\mathrm{Mg}^{2+}$ concentration, the histological damage was intensified and locomotor patterns were inhibited. ${ }^{10}$ The present report sought to characterize the processes responsible for this damage enhancement.

$\mathbf{P M}+\mathbf{M g}^{2+}$ evoked lesion of white matter elements. This solution was confirmed to produce stronger damage than the original PM (without added $\mathrm{Mg}^{2+}$ ), as pyknosis was seen in about $80 \%$ of the ROI white matter elements and was accompanied by early phosphohistone positivity to indicate relatively rapid DNA damage. ${ }^{18}$ The canonical marker of apoptosis, namely, activated caspase $3,{ }^{19}$ was evident in a small minority of white matter cells only. Perhaps the damage had evolved so quickly that cell death had become apparent before any extensive apoptosis could be produced. In keeping with this view was our observation that a pharmacological inhibitor of apoptosis ${ }^{24}$ did not arrest pyknosis, although it reduced pyknosis when coapplied with PJ34, the inhibitor of PARP-1, ${ }^{23}$ which is essential for DNA damage repair and whose hyperactivation generates the toxic product $\mathrm{PAR}^{23,28,29}$ PAR was already strongly increased $3 \mathrm{~h}$ after the end of $\mathrm{PM}+\mathrm{Mg}^{2+}$ application, suggesting a narrow time window before irreversible cell damage could occur (demonstrated by colocalization of PAR and pyknosis). When PJ34 is administered early during the lesion protocol, a degree of functional neuroprotection is observed $^{36}$ in accordance with the present data. In general, the present results suggest that the presence of $\mathrm{Mg}^{2+}$ during the ischemic-like protocol aggravated the damage to the white matter cells by promoting the activation of at least one major cell death pathway, namely, parthanatos.

Gray matter damage by $\mathbf{P M}+\mathbf{M g}^{\mathbf{2}}$. Alongside low-scale pyknosis, most NeuN-positive neurons exhibited a gradient of neuronal loss: the strongest in the ventral horn, a modest one in the dorsal horn, and apparently none in the central region. Motoneurons, however, did not disappear, as their typical marker ChAT was preserved even $24 \mathrm{~h}$ later. These cells were, nevertheless, showing signs of distress because their SMI32 positivity was decreased, suggesting disturbance of their cytoskeleton. Conversely, a traumatic lesion in vivo is associated, a few days later, with loss of ChAT, followed by upregulation of SMI32 expression by surviving motoneurons, taken as an index of cell repair. ${ }^{37}$ The differential evolution of ChAT and SMI32 in the present study compared with in vivo experiments is unlikely due to motoneuronal maturation, as neonatal motoneurons already show adult somatic size. ${ }^{38}$ Accordingly, in the in vitro rat spinal cord model, the number of SMI32- and ChAT-positive cells and their staining pattern remain constant in the first week of life. ${ }^{25}$ Further, AIF-dependent cell death mediates neuronal death after hypoxia-ischemia in the neonatal rat brain $^{39}$ as much as in the adult brain. ${ }^{22}$ Hence, dynamic changes in these two biomarkers may indicate distinct processes and time course underlying either degenerative mechanisms or restoration.

Concomitant with the fall in SMI32 signal was the detection of rising PAR immunoreactivity in the same cells. This was likely a sign of impending death, as it was accompanied by strong AIF translocation into the nucleus, a known effector of cell death. ${ }^{29}$ Interestingly, AIF nuclear translocation was closely associated with loss of NeuN positivity. NeuN is an intrinsic component of the neuronal nuclear matrix, ${ }^{40}$ whose fast degradation (already at $1 \mathrm{~h}$ after injury) ${ }^{41}$ precedes cytoskeletal changes (identified, for instance, with SMI32 positivity) in injured motoneurons. ${ }^{37}$

These results imply that various motoneuron biomarkers should be tested for assessing damage in pathological conditions, as their significance in the diagnosis of cell death is time-dependent. Thus, we surmise that the development of 
a

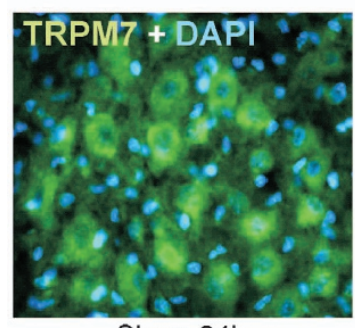

Sham 24h

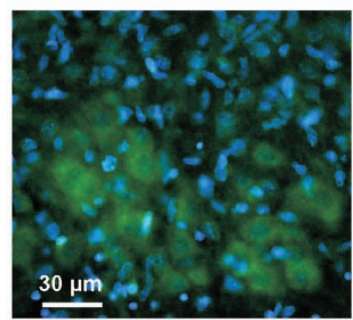

$\mathrm{PM}+\mathrm{Mg}+24 \mathrm{~h}$

C

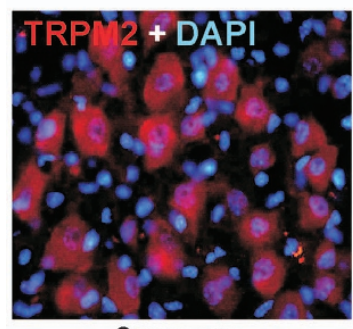

Sham $24 \mathrm{~h}$

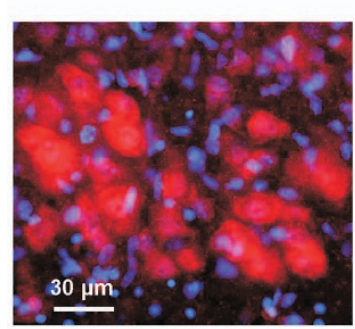

$\mathrm{PM}+\mathrm{Mg}+24 \mathrm{~h}$
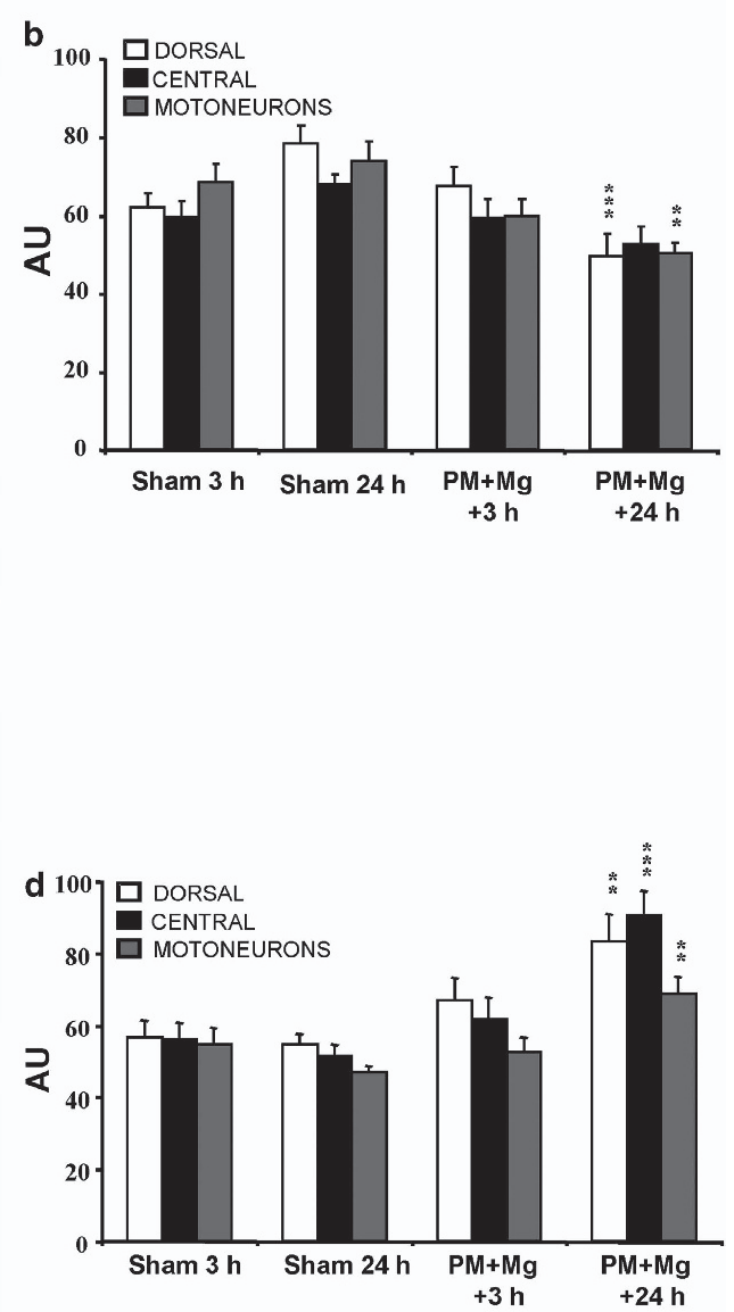

Figure 8 Gray matter expression of TRPM7 or TRPM2 after PM $+\mathrm{Mg}^{2+}$ application. (a) Examples of TRPM7 immunoreactivity in the ventral horn under sham conditions or $24 \mathrm{~h}$ after $\mathrm{PM}+\mathrm{Mg}^{2+}$. (b) Histograms show distribution of TRPM7 immunoreactivity in dorsal, central and motoneuron ROls. Note the significant fall in average signal intensity $24 \mathrm{~h}$ after $\mathrm{PM}+\mathrm{Mg}^{2+}$ for dorsal and motoneuron ROIs; ${ }^{\star *} P=0.002$; ${ }^{* \star \star} P<0.001$. (c) Examples of TRPM2 immunoreactivity in ventral horn under sham conditions or $24 \mathrm{~h}$ after PM $+\mathrm{Mg}^{2+}$. (d) Histograms show distribution of TRPM2 immunoreactivity in dorsal, central and motoneuron ROls. Note the significant increase in TRPM2 signal in all three ROls examined; one-way Anova Tukey test, ${ }^{* \star} P=0.004$; ${ }^{* \star} P<0.001$. All data are from nine spinal sections from three rats

parthanatos in motoneurons occurred on a slower time base than in the white matter. Nevertheless, these pathological changes have a strong negative impact on locomotor network function. ${ }^{10}$

TRPM2 and TRPM7 roles in the $\mathrm{PM}+\mathrm{Mg}^{2+}$ effects. These two membrane channels have recently been investigated for their contribution to ischemic cell death in the brain. ${ }^{13,35}$ These channels are gated open by intracellular $\mathrm{PAR}$, reactive oxygen species and $\mathrm{Mg}^{2+}$ (as under normal conditions such channels are minimally activated). ${ }^{13,14,42-44}$ For these reasons, we studied how these channels were expressed during our experimental protocol. In view of reports on the ubiquitous occurrence of TRPM7 expression, ${ }^{45}$ their immunohistochemical absence in the white matter under sham conditions was not anticipated. This phenomenon could not be attributed to loss of protein expression by keeping the preparation in vitro because analogous lack of signal was found when the tissue was frozen immediately after dissection. It seems feasible that immaturity of the neonatal spinal cord was a factor for poor TRPM7 expression in controls. It was, however, clear that already $3 \mathrm{~h}$ after $\mathrm{PM}+\mathrm{Mg}^{2+}$ exposure a large number of white matter cells (with pyknotic nucleus) were positive to 
TRPM7. Our interpretation is that metabolic distress in the presence of $\mathrm{Mg}^{2+}$ triggered rapid trafficking of TRPM7 proteins to the cell membrane, where their activation might have contributed to the observed damage.

Unlike the white matter cells, in the gray matter, baseline expression of TRPM7 fell in motoneurons and dorsal neurons $24 \mathrm{~h}$ after $\mathrm{PM}+\mathrm{Mg}^{2+}$ when low-scale pyknosis was manifested. TRPM2 expression (that could not be observed in the white matter) showed an opposite pattern with a late rise in gray matter neurons, which was especially strong in the central region. It is not feasible to relate the intensity of immunoreactivity to channel activation; thus, the present results about differential TRPM7 and TRPM2 signal intensities cannot be extrapolated to a specific role of these proteins in neuronal survival or death. Nonetheless, the present observations indicate a significant dichotomy in TRPM7 and TRPM2 channel expression, whose molecular mechanism remains to be clarified. Future studies are necessary to investigate the functional activity of TRPM2 or TRPM7 channels under the present experimental protocols. This goal is, however, complex because of the difficulty to isolate, in an intact network system, the contribution of these conductances in the absence of selective inhibitors, the widespread dysfunction of motoneurons and the lack of knockout rat models.

Even if both TRPM7 and TRPM2 channels have been proposed to be mediators of neuronal death after ischemia, ${ }^{46}$ the time dependence of their differential activation is not known under the present conditions. As TRPM2 channels are inhibited by intracellular glutathione, ${ }^{47}$ TRPM2 overexpression was perhaps related to metabolic dysfunction that developed early for the superficial motoneurons. The effects of the toxic solution on deep central neurons were likely delayed with morphological preservation of such cells that had shown the strongest TRPM2 expression. One hypothesis is that the TRPM2 activation would eventually lead to central neuron damage occurring at the time point beyond the 24-h in vitro survival of the isolated control spinal cord, and thus outside our experimental range. As TRPM2 channels are characterized by small conductance, ${ }^{14}$ it would follow that a small-scale influx of these cations might determine the delayed trigger of parthanatos.

Role of extracellular $\mathbf{M g}^{2+}$. From the point of view of an in vitro spinal model, it is apparent that the standard concentration $(1 \mathrm{mM})$ of $\mathrm{Mg}^{2+}$ amplified white matter damage and extended it to the gray matter. The reason might reside in the differential expression of TRPM7 and TRPM2, plus the degree of PAR hyperproduction at the early stage of damage, because the concentrations of PAR and intracellular $\mathrm{Mg}^{2+}$ are potent modulators of the activity of these channels. ${ }^{13,46}$ Recent studies with in vitro brainstem neurons have proposed that changes in intracellular $\mathrm{Mg}^{2+}$ concentrations occurring during pathological states can affect the conductance of neuronal Cx36 gap junctions ${ }^{48}$ and presumably shape the damage outcome. Although chemical synaptic inputs and Cx36-dependent electrical synapses contribute to synchronization of spinal motoneuron function, ${ }^{49}$ the expressions of $\mathrm{Cx} 36$ and Cx32 mRNA and proteins are sparse and unchanged after rat $\mathrm{SCl}{ }^{50}$ The complexity of the processes underlying ischemia-induced damage in the spinal cord even when studied with an in vitro model implies diversity of molecular pathways with distinct time dependence and cell specificity, factors that contribute to the difficulty of implementing successful neuroprotection in vivo. ${ }^{51-53}$ The present report suggests that the extracellular level of $\mathrm{Mg}^{2+}$ largely affects cell death mechanisms in the spinal cord and extends damage to motoneurons by facilitating the onset of parthanatos.

\section{Materials and Methods}

Rat spinal cord preparation. The experiments were performed on neonatal Wistar rats of postnatal age $0-1$ days in accordance with the guidelines of the National Institutes of Health and the Italian act D.Lgs. 27/1/92 no. 116 (implementing the European Community directives no. 86/609 and 93/88), and the protocols were approved by the SISSA ethical committee for animal experimentation. We minimized the number of animals used in order to allow clear statistical analysis. Spinal cords were carefully dissected out from pups under urethane anesthesia $(0.2 \mathrm{ml}$ i.p. of a $10 \% \mathrm{w} / \mathrm{v}$ solution) at room temperature, with continuous superfusion with Kreb's solution containing (in $\mathrm{mM}$ ) the following: $\mathrm{NaCl}, 113 ; \mathrm{KCl}$, 4.5; $\mathrm{MgCl}_{2} 7 \mathrm{H}_{2} \mathrm{O}, 1 ; \mathrm{CaCl}_{2}, 2 ; \mathrm{NaH}_{2} \mathrm{PO}_{4}, 1 ; \mathrm{NaHCO}_{3}$, 25; glucose, 11; gassed with $95 \% \mathrm{O}_{2} / 5 \% \mathrm{CO}_{2}, \mathrm{pH} 7.4$ at room temperature $\left(22{ }^{\circ} \mathrm{C}\right)$, as described previously. ${ }^{26}$

Protocol for spinal cord lesion. Our aim was to generate an experimental condition that might mimic the acute clinical setting when the metabolic insult is often temporary because of intensive care treatment to correct the metabolic derangement. In accordance with our studies ${ }^{10,11}$ and to simulate the biochemical conditions believed to occur at the site of the lesion, we used a metabolic perturbation protocol consisting of the transient application of PM (see below) with the addition of $1 \mathrm{mM} \mathrm{Mg}{ }^{2+} .{ }^{10}$ This protocol is known to induce a pathological condition that includes locomotor network inhibition and histological damage. ${ }^{10}$ Thus, a solution containing $10 \mathrm{mM} \mathrm{H}_{2} \mathrm{O}_{2}, 500 \mu \mathrm{M}$ sodium nitroprusside (SNP) and $1 \mathrm{mM} \mathrm{Mg}^{2+}$ and lacking oxygen and glucose was applied for $1 \mathrm{~h}$. $\mathrm{NaHCO}_{3}$ was omitted and 4-(2-hydroxyethyl)-1-piperazineethanesulfonic acid (HEPES) was added to reach the pH range of 6.75-6.80 (with $0.1 \mathrm{~N} \mathrm{NaOH}$ ) and the osmolarity was lowered to $230-240 \mathrm{mOsm}$. This solution recapitulates the biochemical derangement believed to occur in the spinal cord after acute non-traumatic injury. ${ }^{9}$

After a 1-h application of $\mathrm{PM}+\mathrm{Mg}^{2+}$, the latter solution was washed out and standard Kreb's solution was superfused again for up to $24 \mathrm{~h}$, after which preparations were fixed as previously reported ${ }^{9}$ and processed for histology as detailed below. Sham experiments were performed by keeping the preparations for analogous times in the same experimental setup without applying a toxic medium.

Quantification of dead cells. Using a Zeiss Axioskop2 microscope (Oberkochen, Germany) and Metavue software (Metamorph suite sold by Molecular Devices, Sunnyvale, CA, USA), cell counting was performed after DAPI staining or NeuN positivity (for neurons). Data were counted with 'eCELLence' (Glance Vision Tech., Trieste, Italy) software. ${ }^{9,10}$ For each histological crosssection of the spinal cord, four different regions were investigated: dorsal gray matter (Rexed laminae I-IV), central gray matter (Rexed laminae V-VII and X), ventral gray matter (Rexed laminae VIII-IX) and ventrolateral white matter. In each region, three to six fields of $280 \times 280-\mu \mathrm{m}$ (gray matter) or $100 \times 280-\mu \mathrm{m}$ (white matter) area were analyzed. For each experimental group, three spinal cords were analyzed and, for each spinal cord, 3-4 different sections from T13 to L3 (thoracic spinal cord segment 13 to lumbar spinal cord segment 3) segments were examined. Pyknosis was readily observed as a change in nuclear morphology resulting from chromatin condensation. ${ }^{54}$

Immunofluorescence procedure. Immunostaining was performed as previously described. ${ }^{9,26}$ Briefly, paraformaldehyde-fixed spinal cords were cryoprotected with $30 \%$ sucrose and sectioned $(30 \mu \mathrm{m})$ with a sliding microtome. In accordance with our former studies, we analyzed spinal regions between $\mathrm{T} 13$ and L3 segments. For all antibodies (except anti-PAR), after incubation in blocking solution ( $5 \%$ normal goat serum, $5 \%$ bovine serum albumin, $0.3 \%$ Triton-X 100) for $1 \mathrm{~h}$ at room temperature, the primary antibody was incubated at $4{ }^{\circ} \mathrm{C}$ overnight. Before incubating tissue sections with the PAR antibody, an 
antigen-retrieval procedure was performed by treating $\left(20 \mathrm{~min}\right.$ at $\left.60^{\circ} \mathrm{C}\right)$ samples with Tromethamine (TRIS) -Ethylenediaminetetraacetic acid (EDTA) - TWEEN 80 $(\mathrm{pH}=8.5)$. To preserve the structure of spinal cord slices that could be damaged by the antigen retrieval procedure, the TRIS-EDTA-TWEEN was washed out with cold phosphate-buffered solution (PBS) five times to stop the reaction before mounting the slices for immunostaining. The primary antibodies were visualized using secondary anti-mouse Alexa fluor 488 or 594 antibodies (1:500; see Supplementary Table 1). Sections were finally stained with DAPI for $20 \mathrm{~min}$ and analyzed as detailed below.

All antibodies (except TRPM2 and TRPM7) have been previously used and validated for immunostaining with our preparations (for ChAT, NeuN, SMI32, see Taccola et al. ${ }^{9}$ and Cifra et al. ${ }^{25}$; for AIF, cleaved caspase-3, H2AX and PAR, see Kuzhandaivel et al..$\left.^{16,21}\right)$. The TRPM2 antibody was validated by Hara et al. ${ }^{55}$ and the TRPM7 antibody by Everaerts et al. ${ }^{56}$

Immunofluorescence data analysis. For each spinal section, images of the dorsal and ventral horns, the area around the central canal and the ventrolateral white matter were acquired with a LEICA 6000 microscope $(\times 40$ lens) using identical capture settings throughout, and ensuring that signals were clearly below saturation and yielding a good signal/noise ratio. For each spinal region, the acquisition procedure was repeated four times at $z$ axis intervals of $1 \mu \mathrm{m}$. In order to analyze all these images, we used the 3D Volocity software (Perkin Elmer, London, UK) applied to four regions of interest (ROIs). For the dorsal, central and white matter regions, the ROI size was $200 \times 100 \mu \mathrm{m}$. For motoneurons, we drew by hand a ventral horn region that comprised large-diameter $(>25 \mu \mathrm{m})$ neurons. For each gray matter ROI, using the 'voxel spy' facility of the software, we calculated the background fluorescence and included in the analysis only those signals that were higher than this threshold value. Owing to the large degree of cell meshing in the neuropile, the ROI signal intensity was evaluated on a gray scale and expressed in arbitrary units (AUs). The data were averaged from three histological sections from each one of three rats. In the case of white matter quantification, it was possible to observe individual cells that were counted and averaged for three sections from each one of three rats.

This approach was employed for quantifying data concerning immunopositivity to PAR, ChAT, SMI32, TRPM2 and TRPM7. For caspase 3, phosphohistone and NeuN data, we used previously published procedures with a Zeiss Axioskop2 microscope and Metavue software. ${ }^{16}$

Analysis of AIF translocation. Images of single motoneurons were acquired with a LEICA confocal microscope, using $0.5-\mu \mathrm{m} \mathrm{z}$ sectioning as reported by $\mathrm{Oh}$ et al. ${ }^{57}$ After reconstructing the cell image, we selected a single central optical section that comprised the largest nuclear staining with DAPI. Thereafter, we performed a line scan of such an image to verify the distribution of AIF immunofluorescence signal in the nucleus and in the cytoplasmic compartment. The number of reconstructed motoneurons showing AIF nuclear translocation was quantified with ImageJ (http://rsb.info.nih.gov/ij).

Nuclear and mitochondrial protein extraction. The nuclear extraction was prepared in accordance with published reports. ${ }^{21,58}$ Thus, isolated spinal cords were washed with ice-cold 250-STMDPS buffer $(50 \mathrm{mM}$ Tris- $\mathrm{HCl}, \mathrm{pH} 7.4$, $250 \mathrm{mM}$ sucrose, $5 \mathrm{mM} \mathrm{MgCl} 2,1 \mathrm{mM}$ dithiothreitol (DTT), $1 \mathrm{mM}$ phenylmethylsulfonyl fluoride (PMSF), $25 \mu \mathrm{g} / \mathrm{ml}$ spermine and $25 \mu \mathrm{g} / \mathrm{ml}$ spermidine) and then submerged in the same. After 15 strokes in a Dounce homogenizer, the extract was centrifuged at $800 \mathrm{~g}$ for $15 \mathrm{~min}$. The pellet (Pellet I) was used to prepare the nuclear fraction. The supernatant was again centrifuged at $6000 \mathrm{~g}$ for $15 \mathrm{~min}$ to remove mitochondria (Pellet II). To prepare the nuclear fraction, Pellet I was homogenized with a single stroke in a Dounce homogenizer in 2 M-STMDPS buffer ( $50 \mathrm{mM}$ Tris- $\mathrm{HCl}, \mathrm{pH} 7.4,2 \mathrm{M}$ sucrose, $5 \mathrm{mM} \mathrm{MgCl} 2,1 \mathrm{mM}$ DTT, $1 \mathrm{mM}$ PMSF, $25 \mu \mathrm{g} / \mathrm{ml}$ spermine, and $25 \mu \mathrm{g} / \mathrm{ml}$ spermidine) and fractionated at $80000 \mathrm{~g}$ for $5 \mathrm{~min}$. The resulting pellet was resuspended in nuclear extract buffer $(20 \mathrm{mM}$ HEPES, pH 7.9, $1.5 \mathrm{mM} \mathrm{MgCl}_{2}, 0.5 \mathrm{M} \mathrm{NaCl}, 0.2 \mathrm{mM}$ EDTA, and $20 \%$ glycerol) and used as the nuclear fraction (Pellet I). Pellet II was resuspended in hypotonic lysis buffer (10 mM HEPES, pH 7.9, $1 \mathrm{mM}$ DTT, plus the protease inhibitor cocktail; Sigma, Milan, Italy) and incubated on ice for $30 \mathrm{~min}$. The suspension was sonicated to lyse mitochondria. Protein concentrations were determined for the nuclear fraction and the mitochondrial lysate using the standard bicinchoninic acid assay following the manufacturer's protocol (Sigma). For each individual experiment, three spinal cords were used. The purity of the extracted nuclear fraction was validated by looking for (with western immunoblotting) any mitochondrial contamination indicated by the cytochrome $C$ oxidase IV protein (Abcam, Cambridge, UK) in accordance with the method of Beirowski et al. ${ }^{59}$ These samples were then used for ELISA.

ELISA quantification of PAR. To obtain evidence for PARP-1 activation and pharmacological inhibition by $\mathrm{N}$-(5, 6-Dihydro-6-oxo-2-phenanthridinyl)-2acetamide (PJ34), we quantified its product PAR in accordance with Nasrabady et $a l^{60}$ For this purpose, lysates of spinal cords treated with $\mathrm{PM}+\mathrm{Mg}$ and/or PJ34, or in sham conditions, were collected $24 \mathrm{~h}$ later and their PAR levels were measured using the PARP in vivo pharmacodynamic assay II (http//www.trevigen.com/protocols) following the manufacturer's protocol (Trevigen, Bologna, Italy). This assay is based on ELISA immunoreactivity resulting in chemiluminescence signals recorded with a Glomax multi-detection system (Promega, Milan, Italy). Whenever tests were performed for the action of PJ34, this substance was added to the cell lysis buffer to avoid inhibitor dilution as per the manufacturer's instructions. All samples were run in duplicate. After background subtraction (blank samples), the net PAR levels were quantified using a standard linear plot $(r=0.98)$ based on the immunoreactivity induced by known concentrations $(20-1000 \mathrm{pg} / \mathrm{ml})$ of PAR. Data were expressed as $\mathrm{pg} / \mathrm{ml} /$ $100 \mu \mathrm{g}$ of protein (estimated as indicated below).

Drugs. SNP and PJ34 were purchased from Sigma; $\mathrm{H}_{2} \mathrm{O}_{2}$ was obtained from Carlo Erba Reagents (Milan, Italy); and active caspase 3 inhibitor II was obtained from CalBiochem-Millipore (Billerica, MA, USA).

Data analysis. The data are shown as mean \pm S.D. Statistical analysis was carried out with SigmaStat 3.1 (Systat Software, Chicago, IL, USA). Parametric and nonparametric data were first distinguished with a normality test (Anova Tukey) and analyzed with the Student $t$-test and the Mann-Whitney test, respectively, in accordance with the software choice. The significance level was always $P<0.05$, and $n$ indicates the number of tissue sections.

\section{Conflict of Interest}

The authors declare no conflict of interest.

Acknowledgements. We thank our colleague Dr. A Kuzhandaivel for her help with the ELISA assay, Dr. Micaela Grandolfo for support with quantitative image analysis and Dr. Andrea Tomicich for software support. This work was supported by a grant from the government of the Friuli Venezia Giulia Region (SPINAL project).

1. van den Berg ME, Castellote JM, Mahillo-Fernandez I, de Pedro-Cuesta J. Incidence of spinal cord injury worldwide: a systematic review. Neuroepidemiology 2010; 34: 184-192.

2. Lin MC, Huang YL, Liu HW, Yang DY, Lee CP, Yang LL et al. On-line microdialysisgraphite furnace atomic absorption spectrometry in the determination of brain magnesium levels in gerbils subjected to cerebral ischemia/reperfusion. J Am Coll Nutr 2004; 23: 561S-565SS.

3. Valadka AB, Goodman JC, Gopinath SP, Uzura M, Robertson CS. Comparison of brain tissue oxygen tension to microdialysis-based measures of cerebral ischemia in fatally head-injured humans. J Neurotrauma 1998; 15: 509-519.

4. Maas Al, Murray GD. Magnesium for neuroprotection after traumatic brain injury. Lancet Neurol 2007; 6: 20-21.

5. Temkin NR, Anderson GD, Winn HR, Ellenbogen RG, Britz GW, Schuster J et al. Magnesium sulfate for neuroprotection after traumatic brain injury: a randomised controlled trial. Lancet Neurol 2007; 6: 29-38.

6. IMAGES.. Magnesium for acute stroke (Intravenous Magnesium Efficacy in Stroke Trial): randomised controlled trial. Lancet 2004; 363: 439-445.

7. Perlman JM. Intervention strategies for neonatal hypoxic-ischemic cerebral injury. Clin Ther 2006; 28: 1353-1365.

8. Saeki H, Matsumoto M, Kaneko S, Tsuruta S, Cui YJ, Ohtake K et al. Is intrathecal magnesium sulfate safe and protective against ischemic spinal cord injury in rabbits? Anesth Analg 2004; 99: 1805-1812.

9. Taccola G, Margaryan G, Mladinic M, Nistri A. Kainate and metabolic perturbation mimicking spinal injury differentially contribute to early damage of locomotor networks in the in vitro neonatal rat spinal cord. Neuroscience 2008; 155: 538-555. 
10. Margaryan G, Mladinic M, Mattioli C, Nistri A. Extracellular magnesium enhances the damage to locomotor networks produced by metabolic perturbation mimicking spinal injury in the neonatal rat spinal cord in vitro. Neuroscience 2009; 163: 669-682.

11. Ryazanova LV, Rondon LJ, Zierler S, Hu Z, Galli J, Yamaguchi TP et al. TRPM7 is essential for $\mathrm{Mg}^{2+}$ homeostasis in mammals. Nat Commun 2010; 1: 109.

12. Schmitz C, Perraud AL, Johnson CO, Inabe K, Smith MK, Penner R et al. Regulation of vertebrate cellular $\mathrm{Mg}^{2+}$ homeostasis by TRPM7. Cell 2003; 114: 191-200.

13. Aarts MM, Tymianski M. TRPMs and neuronal cell death. Pflugers Arch 2005; 451 243-249.

14. Kühn FJ, Heiner I, Lückhoff A. TRPM2: a calcium influx pathway regulated by oxidative stress and the novel second messenger ADP-ribose. Pflugers Arch 2005; 451 212-219.

15. Sumoza-Toledo A, Penner R. TRPM2: a multifunctional ion channel for calcium signalling J Physiol 2011; 589: 1515-1525.

16. Kuzhandaivel A, Margaryan G, Nistri A, Mladinic M. Extensive glial apoptosis develops early after hypoxic-dysmetabolic insult to the neonatal rat spinal cord in vitro. Neuroscience 2010; 169: 325-338

17. Kuzhandaivel A, Nistri A, Mazzone GL, Mladinic M. Molecular mechanisms underlying cell death in spinal networks in relation to locomotor activity after acute injury in vitro. Front Cell Neurosci 2011; 5: 9.

18. Plesca D, Mazumder S, Almasan A. DNA damage response and apoptosis. Methods Enzymol 2008; 446: 107-122.

19. Cohen GM. Caspases: the executioners of apoptosis. Biochem J 1997; 326: 1-16.

20. Cook PJ, Ju BG, Telese F, Wang X, Glass CK, Rosenfeld MG. Tyrosine dephosphorylation of H2AX modulates apoptosis and survival decisions. Nature 2009; 458: 591-596.

21. Kuzhandaivel $A$, Nistri $A$, Mladinic $M$. Kainate-mediated excitotoxicity induces neuronal death in the rat spinal cord in vitro via a PARP-1 dependent cell death pathway (Parthanatos). Cell Mol Neurobiol 2010; 30: 1001-1012.

22. Wang Y, Dawson VL, Dawson TM. Poly(ADP-ribose) signals to mitochondrial AlF: a key event in parthanatos. Exp Neurol 2009; 218: 193-202.

23. Abdelkarim GE, Gertz K, Harms C, Katchanov J, Dirnagl U, Szabó C et al. Protective effects of PJ34, a novel, potent inhibitor of poly(ADP-ribose) polymerase (PARP) in in vitro and in vivo models of stroke. Int $\mathrm{J} \mathrm{Mol} \mathrm{Med} \mathrm{2001;} \mathrm{7:} \mathrm{255-260.}$

24. Vandenabeele $P$, Vanden Berghe T, Festiens N. Caspase inhibitors promote alternative cell death pathways. Sci STKE 2006; 2006: pe44

25. Cifra A, Mazzone GL, Nani F, Nistri A, Mladinic M. Postnatal developmental profile of neurons and glia in motor nuclei of the brainstem and spinal cord, and its comparison with organotypic slice cultures. Dev Neurobiol 2012; 72: 1140-1160.

26. Mladinic M, Nistri A, Taccola G. Acute spinal cord injury in vitro: insight into basic mechanisms. In Aldskogius H (ed) Animal Models in Spinal Cord Repair. Springer Science + Business Media, LLC. Humana Press: Heidelberg/New York, 2013, pp 39-63.

27. Carriedo SG, Yin HZ, Lamberta R, Weiss JH. In vitro kainate injury to large SMI-32+ spinal neurons is Ca2 + dependent. Neuroreport 1995; 6: 945-948.

28. Andrabi SA, Kim NS, Yu SW, Wang H, Koh DW, Sasaki M et al. Poly(ADP-ribose) (PAR) polymer is a death signal. Proc Natl Acad Sci USA 2006; 103: 18308-18313.

29. Yu SW, Andrabi SA, Wang H, Kim NS, Poirier GG, Dawson TM et al. Apoptosis-inducing factor mediates poly(ADP-ribose) (PAR) polymer-induced cell death. Proc Natl Acad Sci USA 2006; 103: 18314-18319.

30. Susin SA, Lorenzo HK, Zamzami N, Marzo I, Snow BE, Brothers GM et al. Molecular characterization of mitochondrial apoptosis-inducing factor. Nature 1999; 397: 441-446.

31. Venkatachalam K, Montell C. TRP channels. Annu Rev Biochem 2007; 76: 387-417.

32. McNulty S, Fonfria E. The role of TRPM channels in cell death. Pflugers Arch 2005; 451 : 235-242.

33. Miller BA. The role of TRP channels in oxidative stress-induced cell death. J Membr Biol 2006; 209: 31-41.

34. Nicotera $P$, Bano $D$. The enemy at the gates. $C a 2+$ entry through TRPM7 channels and anoxic neuronal death. Cell 2003; 115: 768-770.

35. Sun HS, Jackson MF, Martin LJ, Jansen K, Teves L, Cui H et al. Suppression of hippocampal TRPM7 protein prevents delayed neuronal death in brain ischemia Nat Neurosci 2009; 12: 1300-1307.

36. Nasrabady SE, Kuzhandaivel A, Mladinic M, Nistri A. Effects of 6(5H)-phenanthridinone, an inhibitor of poly(ADP-ribose)polymerase-1 activity (PARP-1), on locomotor networks of the rat isolated spinal cord. Cell Mol Neurobiol 2011; 31: 503-508.

37. Penas C, Casas C, Robert I, Forés J, Navarro X. Cytoskeletal and activity-related changes in spinal motoneurons after root avulsion. J Neurotrauma 2009; 26: 763-779.
38. Carrascal L, Nieto-Gonzalez JL, Cameron WE, Torres B, Nunez-Abades PA. Changes during the postnatal development in physiological and anatomical characteristics of rat motoneurons studied in vitro. Brain Res Brain Res Rev 2005; 49: 377-387.

39. Zhu C, Qiu L, Wang X, Hallin U, Candé C, Kroemer G et al. Involvement of apoptosis-inducing factor in neuronal death after hypoxia-ischemia in the neonatal rat brain. J Neurochem 2003; 86: 306-317.

40. Dent MA, Segura-Anaya E, Alva-Medina J, Aranda-Anzaldo A. NeuN/Fox-3 is an intrinsic component of the neuronal nuclear matrix. FEBS Lett 2010; 584: 2767-2771.

41. Giordano G, Sánchez-Pérez AM, Montoliu C, Berezney $R$, Malyavantham $K$ Costa LG et al. Activation of NMDA receptors induces protein kinase A-mediated phosphorylation and degradation of matrin 3. Blocking these effects prevents NMDA-induced neuronal death. J Neurochem 2005; 94: 808-818.

42. Chen HC, Su LT, González-Pagán O, Overton JD, Runnels LW. A key role for $\mathrm{Mg}^{2+}$ in TRPM7's control of ROS levels during cell stress. Biochem J 2012; 445: 441-448.

43. Cook NL, Van Den Heuvel C, Vink R. Are the transient receptor potential melastatin (TRPM) channels important in magnesium homeostasis following traumatic brain injury? Magnes Res 2009; 22: 225-234.

44. Scharenberg AM. TRPM2 and TRPM7: channel/enzyme fusions to generate novel intracellular sensors. Pflugers Arch 2005; 451: 220-227.

45. Penner R, Fleig $\mathrm{A}$. The $\mathrm{Mg}^{2+}$ and $\mathrm{Mg}^{2+}$-nucleotide-regulated channel-kinase TRPM7. Handb Exp Pharmacol 2007; 179: 313-328.

46. Xie YF, Macdonald JF, Jackson MF. TRPM2 calcium and neurodegenerative diseases. Int J Physiol Pathophysiol Pharmacol 2010; 2: 95-103.

47. Belrose JC, Xie YF, Gierszewski LJ, MacDonald JF, Jackson MF. Loss of glutathione homeostasis associated with neuronal senescence facilitates TRPM2 channel activation in cultured hippocampal pyramidal neurons. Mol Brain 2012; 5: 11.

48. Palacios-Prado N, Hoge G, Marandykina A, Rimkute L, Chapuis S, Paulauskas N et al. Intracellular magnesium-dependent modulation of gap junction channels formed by neuronal connexin36. J Neurosci 2013; 33: 4741-4753.

49. Tresch MC, Kiehn O. Synchronization of motor neurons during locomotion in the neonatal rat: predictors and mechanisms. J Neurosci 2002; 22: 9997-10008.

50. Lee IH, Lindqvist E, Kiehn O, Widenfalk J, Olson L. Glial and neuronal connexin expression patterns in the rat spinal cord during development and following injury. J Comp Neurol 2005; 489: 1-10.

51. Faden Al, Stoica B. Neuroprotection: challenges and opportunities. Arch Neurol 2007; 64: 794-800

52. Savitz SI, Fisher M. Future of neuroprotection for acute stroke: in the aftermath of the SAINT trials. Ann Neurol 2007; 61: 396-402.

53. Thuret S, Moon LD, Gage FH. Therapeutic interventions after spinal cord injury. Nat Rev Neurosci 2006; 7: 628-643.

54. Burgoyne LA. The mechanisms of pyknosis: hypercondensation and death. Exp Cell Res 1999; 248: 214-222.

55. Hara Y, Wakamori M, Ishii M, Maeno E, Nishida M, Yoshida T et al. LTRPC2 $\mathrm{Ca}^{2+}{ }_{-}$ permeable channel activated by changes in redox status confers susceptibility to cell death. Mol Cell 2002; 9: 163-173.

56. Everaerts W, Vriens J, Owsianik G, Appendino G, Voets T, De Ridder D et al. Functional characterization of transient receptor potential channels in mouse urothelial cells. Am J Physiol Renal Physiol 2010; 298: F692-F701.

57. Oh YK, Shin KS, Kang SJ. AIF translocates to the nucleus in the spinal motor neurons in a mouse model of ALS. Neurosci Lett 2006; 406: 205-210.

58. Cox B, Emili A. Tissue subcellular fractionation and protein extraction for use in mass-spectrometry-based proteomics. Nat Protoc 2006; 1: 1872-1878.

59. Beirowski B, Babetto E, Gilley J, Mazzola F, Conforti L, Janeckova L et al. Non-nuclear WId(S) determines its neuroprotective efficacy for axons and synapses in vivo. J Neurosci 2009; 29: 653-668.

60. Nasrabady SE, Kuzhandaivel A, Nistri A. Studies of locomotor network neuroprotection by the selective poly(ADP-ribose) polymerase-1 inhibitor PJ-34 against excitotoxic injury to the rat spinal cord in vitro. Eur J Neurosci 2011; 33: 2216-2227.

(c) (i) $(9)$ Cell Death and Disease is an open-access journal published by Nature Publishing Group. This work is licensed under a Creative Commons Attribution-NonCommercialNoDerivs 3.0 Unported License. To view a copy of this license, visit http://creativecommons.org/licenses/by-nc-nd/3.0/

\section{Supplementary Information accompanies this paper on Cell Death and Disease website (http://www.nature.com/cddis)}

